\section{Self-reported camouflaging behaviours used by autistic adults during everyday social interactions}

Autism

(C) The Author(s) 2021 (c) (i) \$

Article reuse guidelines: sagepub.com/journals-permissions DOI: 10.1 | 77// 36236|32। I026754 journals.sagepub.com/home/aut

(S)AGE

\author{
Julia Cook $(\mathbb{D}$, Laura Crane $(\mathbb{D}$, Laura Hull $(\mathbb{D}$, \\ Laura Bourne and William Mandy (iD
}

\begin{abstract}
Autistic people may camouflage their innate autistic social behaviours to adapt to, cope within and/or influence the predominately neurotypical social landscape. This study describes behaviours exhibited, altered or avoided by autistic adults whilst camouflaging (i.e. camouflaging behaviours). Using Interpersonal Process Recall methodology, 17 autistic adults ( 8 women, 6 men and 3 agender/gender neutral individuals) participated in a brief social task designed to replicate a common day-to-day social situation. Participants then watched a video of their interaction with a researcher, actively identifying and describing camouflaging behaviours. Using qualitative content analysis, descriptions of 38 camouflaging behaviours described by participants were clustered into four main categories and seven subcategories: (I) masking, (2) innocuous engagement (subcategories: passive encouragement, centring social partner, deferential engagement and reducing social risk), (3) modelling neurotypical communication and (4) active self-presentation (subcategories: reciprocal social behaviours, risky social behaviours, and comfortable and familiar social behaviours). The novel use of Interpersonal Process Recall methodology addressed limitations in existing camouflaging research and facilitated the identification of previously unreported camouflaging behaviours. These camouflaging behaviours are discussed with reference to literature concerning interpersonal research and theory within and outside the field of autism.
\end{abstract}

\title{
Lay abstract
}

Camouflaging can be thought of as the process through which autistic people modify their natural social behaviours to adapt to, cope within or influence the largely neurotypical (non-autistic) social world. Many autistic people experience negative reactions to their natural or intuitive social behaviours when interacting with non-autistic people. Over time, in response to these negative reactions, autistic people's social behaviour often changes. We refer to autistic people's changed behaviours as 'camouflaging behaviours'. Research exploring camouflaging behaviours is still at an early stage. This study investigated camouflaging behaviours used by autistic adults in everyday social interactions using a research method that was new to the field of autism. Specifically, 17 autistic adults were filmed taking part in a common everyday social situation - a conversation with a stranger. With the help of the video of this conversation, they then showed and described their camouflaging behaviours to a researcher. These autistic people identified and described a total of 38 different camouflaging behaviours. The detailed and specific information provided by autistic adults about camouflaging behaviours generated important new insights into the ways in which autistic people adapt to, cope within and influence the neurotypical (non-autistic) social world.

\section{Keywords}

autism, camouflaging, masking, social behaviour

During social interactions between autistic and non-autistic people, factors contributing to communication, reciprocity and rapport problems are both numerous and complex (double empathy problem; Milton, 2012). Autistic and non-autistic people differ in their use of, for example, pragmatic language (de Villiers, Fine, Ginsberg, Vaccarella,
University College London, UK

\section{Corresponding author:}

Julia Cook, Research Department of Clinical, Educational and Health Psychology, University College London, I-19 Torrington Place, London WCIE 6BT, UK.

Email: Julia.cook.18@ucl.ac.uk 
\& Szatmari, 2007; Sng, Carter, Stephenson, \& Sweller, 2020), eye gaze (Papagiannopoulou, Chitty, Hermens, Hickie, \& Lagopoulos, 2014), facial expressivity (Faso, Sasson, \& Pinkham, 2015) and gesture (de Marchena \& Eigsti, 2010). Just as autistic people have difficulties in inferring non-autistic mental states, understanding nonautistic social communication and maintaining social reciprocity with non-autistic people (American Psychiatric Association, 2013; Baron-Cohen, Jolliffe, Mortimore, \& Robertson, 1997; Frith \& Happé, 1994), non-autistic people likewise experience difficulties in inferring autistic mental states (Edey et al., 2016), identifying autistic facial expressions (Sheppard, Pillai, Wong, Ropar, \& Mitchell, 2016) and effectively sharing information and building rapport with autistic (compared to non-autistic) peers (Crompton, Ropar, Evans-Williams, Flynn, \& FletcherWatson, 2020). Moreover, non-autistic people demonstrate an ingroup preference for their interpersonal style; forming more negative judgements about and less positive behavioural intentions towards individuals displaying autistic behaviours than individuals without autistic behaviours (Campbell, Ferguson, Herzinger, Jackson, \& Marino, 2004; Morrison, DeBrabander, Faso, \& Sasson, 2019; Sasson et al., 2017; Sasson \& Morrison, 2019). Such issues likely contribute to poor functional and interpersonal outcomes for autistic people in domains such as social participation and relationships (Billstedt, Gillberg, \& Gillberg, 2011; Orsmond, Shattuck, Cooper, Sterzing, \& Anderson, 2013), employment (Howlin, Goode, Hutton, \& Rutter, 2004) and mental health (Lever \& Geurts, 2016).

An emerging line of research concerned with social coping examines ways in which autistic people camouflage during social interactions with non-autistic people (i.e. during 'cross-neurotype' interactions: Dean, Harwood, \& Kasari, 2017; Hull et al., 2017; Lai et al., 2017; Schuck, Flores, \& Fung, 2019). Conceptualisations, definitions and measures of camouflaging are in their infancy. Here, we conceptualise camouflaging as the dynamic process through which autistic individuals modify their innate autistic social behaviour to adapt to, cope within and/or influence the predominately neurotypical social environment. Autistic people commonly encounter negative reactions to their personal characteristics and behaviours during social interactions (Kinnear, Link, Ballan, \& Fischbach, 2016; Milton, 2012; Milton, Heasman, \& Sheppard, 2018; Sasson et al., 2017; Sasson \& Morrison, 2019). As a result of such reactions, some autistic people modify their innate or instinctive social behaviour (Hull et al., 2017; Lawson, 2020; Livingston, Shah, \& Happé, 2019; Pearson \& Rose, 2021). In modifying their behaviour, autistic people likely engage multiple cognitive functions involving monitoring the social environment, monitoring of personal behaviours and social reasoning (or proxy social reasoning via non-social cognitive routes; Livingston \& Happé, 2017). However, the extent to which an individual consciously engages in a process of behaviour change or is even aware of behaviour change may vary widely (Lawson, 2020). This modified social behaviour (i.e. camouflaging behaviour) may resemble neurotypical social style, hide autistic characteristics or minimise the visibility to social difficulties (Hull et al., 2017).

Camouflaging is one means through which autistic people attempt to overcome social challenges within crossneurotype social interactions to secure employment and education, develop friendships and romantic relationships, and even avoid harassment and victimisation (Cage \& Troxell-Whitman, 2019; Hull et al., 2017). Qualitative research about autistic experience suggests that camouflaging positively influences the reactions and behaviours of non-autistic people towards autistic people (Hull et al., 2017; Livingston, Shah, \& Happé, 2019). Yet the act of camouflaging is cognitively effortful and taxing; prone to breakdown under increased social demands and complexity and/or psychological distress; and associated with increased mental health difficulties (Beck, Lundwall, Gabrielsen, Cox, \& South, 2020; Cage \& Troxell-Whitman, 2019; Cassidy et al., 2019; Hull et al., 2021; Lai et al., 2017; Livingston, Colvert, Social Relationships Study Team Bolton, \& Happé, 2019) Thus, in seeking to improve the overall well-being of autistic people, it is important to understand the mechanisms through which camouflaging may lead to disparate social, functional and health outcomes. Currently, very little is known about the extent to which camouflaging affects cross-neurotype social interactions and, in turn, impacts social and functional outcomes for autistic people.

The way in which an individual is perceived and treated by their social partner/s during any given social interaction depends on a complex interplay of factors related to both the individual and their social partner/s as well as the circumstances of the social interaction (Cuddy, Fiske, \& Glick, 2008; Morrison et al., 2019; Xie, Flake, \& Hehman, 2019). Nevertheless, individuals influence, and are influenced by, the behaviour of their social partner/s (De Jaegher, 2013; Forgeot d'Arc \& Soulières, 2019). Research with non-autistic people suggests that distinct subtypes of verbal and non-verbal behaviours function within specific interpersonal situations to invite distinct interpersonal reactions and behaviours from others. For example, experimental studies demonstrate that: individuals who disclose more personal information during getting-to-know-you conversations are rated as more likeable (Sprecher, Treger, \& Wondra, 2013), individuals who ask more follow-up questions during speed dating situations are more likely to elicit agreement for a second date (Huang, Yeomans, Brooks, Minson, \& Gino, 2017) and individuals who smile less during job interviews are rated as more suitable candidates for roles associated with a serious demeanour (Ruben, Hall, \& Schmid Mast, 2015). In the case of camouflaging, a detailed description and understanding of both 
camouflaging behaviour as well as the immediate interpersonal consequences of such behaviours is required to delineate relationships between camouflaging and various social and functional outcomes. The development of such an understanding is impacted by the complex and nuanced nature of camouflaging and the associated challenges this poses in using established methodological paradigms and psychological measures to investigate it.

One line of research, using an existing diagnostic observational measure, has demonstrated that in clinical settings, some autistic individuals are rated as appearing less autistic and more normatively socially skilled than would be expected given their autistic traits and social cognition differences (Corbett et al., 2021; Lai et al., 2017, 2019; Livingston, Colvert, et al., 2019; Schuck et al., 2019). However, this approach, based on an observational assessment designed to measure the presence or absence of behaviours for the expressed purpose of an autism diagnostic assessment, is limited in describing the full range of camouflaging behaviours exhibited by autistic people in more naturalistic social environments. Other observational research has documented the camouflaging behaviour of autistic children in school playgrounds, using both a structured observational assessment of social engagement and qualitative observer descriptions (Dean et al., 2017). While this approach goes further in describing camouflaging behaviours in a more naturalistic setting, descriptions of behaviours collected from a distance by neurotypical observers may be both imprecise and constrained by neurotypical conceptualisations of social behaviour.

A further line of research, focused on investigating the phenomenology of camouflaging, has identified and described components of the camouflaging process based on autistic adults' responses in qualitative questionnaires (Hull et al., 2017; Livingston, Shah, \& Happé, 2019). Based on this research, Livingston et al. (2020) created the Compensation Checklist (a list of strategies containing four types of behaviours: masking, shallow compensation, deep compensation and accommodation behaviours), while Hull et al. (2019) developed a self-report measure of camouflaging entitled the Camouflaging Autistic Traits Questionnaire (CAT-Q), comprising of three subscales (compensation, masking, and assimilation behaviours). This approach, based on the real-life experiences of autistic people, promotes the development of an ecologically valid description of camouflaging that is not unduly biased by the preconceptions of researchers and clinicians. However, given camouflaging behaviours as well as the social interactions in which these behaviours occur are often numerous and complex, it may be difficult for participants to retrospectively free-recall all their camouflaging behaviours.

Furthermore, camouflaging behaviours that are more immediately accessible in participants' memories may be selectively reported over less accessible behaviours, particularly those that are pre-verbal or not-verbalised (Larsen, Flesaker, \& Stege, 2008; Omodei, McLennan, \& Wearing, 2005). Overall, given these methodological limitations, we suggest further investigation is required to develop a detailed description and understanding of camouflaging behaviour.

\section{This study}

The aim of this study was to broaden the current understanding of camouflaging by describing behaviours exhibited, altered or avoided by autistic adults while camouflaging (i.e. camouflaging behaviours). Following Interpersonal Process Recall methodology (IPR; Kagan, Schauble, Resnikoff, Danish, \& Krathwohl, 1969), participants took part in a short, quasi-everyday social interaction with a stranger and then completed a semi-structured interview while viewing the audio-visual recording of their earlier social interaction. During the interview, participants actively identified and described camouflaging attempts.

While new to the field of autism, IPR methodology has been used in psychotherapy, education and health research to systematically investigate interpersonal interactions and processes (Bartz, 1999; Burgess, Rhodes, \& Wilson, 2013; Larsen et al., 2008; Marsh, 1983). IPR is designed to address limitations associated with qualitative research retrospectively exploring individuals' conscious experiences of interpersonal interactions weeks, months or years after they have occurred (Larsen et al., 2008). In the case of camouflaging, interviewing participants immediately after a camouflaging experience may allow participants to easily and vividly recall camouflaging behaviours. The use of video during the interview may also cue participants to recall camouflaging behaviour that would not otherwise be recalled unassisted (Omodei et al., 2005; Omodei \& McLennan, 1994). Finally, the slow pace of the IPR interview may allow participants more time to recall and verbalise nuanced, complex or infrequent camouflaging behaviours. Through the novel use of IPR methodology, we aim to identify and describe camouflaging behaviours operating within conscious awareness, not previously reported in existing camouflaging research.

\section{Methods}

\section{Participants and recruitment}

Participants were 17 autistic adults ( 8 women, 6 men and 3 agender/gender neutral individuals) recruited via social media and through London-based autism support groups. Inclusion criteria were (1) aged over 18 years; (2) formally diagnosed with autism by an appropriate healthcare professional and/or multidisciplinary team; (3) IQ in the average/above average range; and (4) indicated at least neutral endorsement of camouflaging behaviours on the CAT-Q 
Table I. Participant characteristics.

\begin{tabular}{|c|c|}
\hline $\mathrm{N}$ & 17 \\
\hline Age (mean years) & 44.53 (SD I2.03) \\
\hline Age range & $24-63$ \\
\hline Age at diagnosis (mean years) & 41.71 (SD I2.18) \\
\hline IQ & I I 2.47 (SD 4.65) \\
\hline $\mathrm{AQ}$ & 39.7I (SD 6.02) \\
\hline CAT-Q & |32.7| (SD |8.I) \\
\hline \multicolumn{2}{|l|}{ Ethnicity, N (\%) } \\
\hline White British & $12(70.6)$ \\
\hline White other & $3(17.6)$ \\
\hline Mixed (other mixed background) & I (5.9) \\
\hline Hispanic & I (5.9) \\
\hline \multicolumn{2}{|l|}{ Education, N (\%) } \\
\hline $\mathrm{PhD}$ & I (5.9) \\
\hline Master's degree & $7(4 \mid .2)$ \\
\hline Bachelor's degree & $8(47.1)$ \\
\hline A-levels (16-18years) & I (5.9) \\
\hline \multicolumn{2}{|l|}{ Occupation, N (\%) } \\
\hline Working full-time & $6(35.3)$ \\
\hline Working part-time & $7(4 \mid .2)$ \\
\hline Voluntary employment & $2(11.8)$ \\
\hline Caring duties & I (5.9) \\
\hline Student & $4(23.5)$ \\
\hline Unknown & I (5.9) \\
\hline \multicolumn{2}{|l|}{ Current living circumstances, N (\%) } \\
\hline Lives independently & $17(100)$ \\
\hline
\end{tabular}

Percentage may not sum $100 \%$ because of rounding. Mixed Other indicates mixed ethnicity other than Asian and White or Black and White. White Other indicates White ethnicity other than White British or Irish. Occupational categories not mutually exclusive.

(i.e. a total CAT-Q score of 100 or above, representing an average item response between 4 (neither agree nor disagree) and 7 (strongly agree); Hull et al., 2019). Five additional autistic adults enrolled in the study; however, their incomplete data were not analysed; one did not meet eligibility criteria, one withdrew before attending the lab and three attended the lab but did not complete the full experimental procedure. Demographic characteristics of included participants are in Table 1.

\section{Procedure}

Ethical approval was obtained from the University College London Research Ethics Committee. Interested individuals were provided with information sheets and given the opportunity to discuss the study with the experimenter (J.C.). Participants then provided their informed written consent and completed a demographic questionnaire, as well as self-report measures of autistic traits (Autism Quotient; Baron-Cohen, Wheelwright, Skinner, Martin, \& Clubley, 2001) and camouflaging (CAT-Q; Hull et al., 2019) online. Eligible participants were then invited to attend the laboratory to complete the testing session.
During the approximately 90-min testing session, participants completed a brief measure of intellectual ability (Test of Premorbid Functioning-UK Version; Wechsler, 2009) and, where possible (in 16 cases), provided written confirmation of their autism diagnosis. Participants additionally completed a controlled social task. This task involved having a 10-min open-ended conversation with a female non-autistic research assistant who was trained to consistently engage with participants in a friendly yet reserved manner following a protocol modelled on prior research (Inderbitzen-Nolan, Anderson, \& Johnson, 2007; Plasencia, Alden, \& Taylor, 2011; Taylor \& Alden, 2010). Prior to beginning the social task, participants were informed they would be spending approximately 10 min conversing with a stranger and asked to act as they normally would when meeting a stranger that they wished to make a good social impression on. Immediately after the social task, participants completed a semi-structured IPR interview while viewing an audio-visual recording of their earlier social task. During the interview, participants were asked to stop the video each time they observed themselves engaging in camouflaging or thinking about engaging in camouflaging. When necessary, the experimenter asked the participant clarifying questions (i.e. to describe what they did or said) to clearly establish observable instances of camouflaging (i.e. descriptions of behaviours exhibited, altered or avoided by participants). Following the participant's lead, the experimenter then asked the participant follow-up questions about their internal (e.g. their thoughts, emotions and motivations) and past experiences (e.g. how the participant learnt the behaviour) related to their behaviour. As a result, participants spontaneously identified additional examples of camouflaging strategies they used in other everyday social interactions. Please see the study by Cook, Crane, Bourne, Hull, \& Mandy (2021) for full methodological details.

\section{Community involvement}

We did not use a participatory or co-design approach. Where appropriate, we followed AASPIRE guidelines for conducting research with autistic participants (Nicolaidis et al., 2019). For example, we (1) assumed participants had decisional capacity, unless proven otherwise, (2) adapted participant information and consent forms to increase accessibility, (3) provided participants with detailed information about lab-based components of the study via phone or email depending on participants' preference, (4) invited participants to complete consent forms and questionnaire measures online in their own time to reduce participant burden, (5) used concrete questions in our interview schedule and (6) clearly explained to participants that they could take a break or stop entirely at any time without having to give a reason. Unfortunately, due to the unique IPR methodology used in the study, it was not possible to offer multimodes of participation as suggested in these guidelines. 


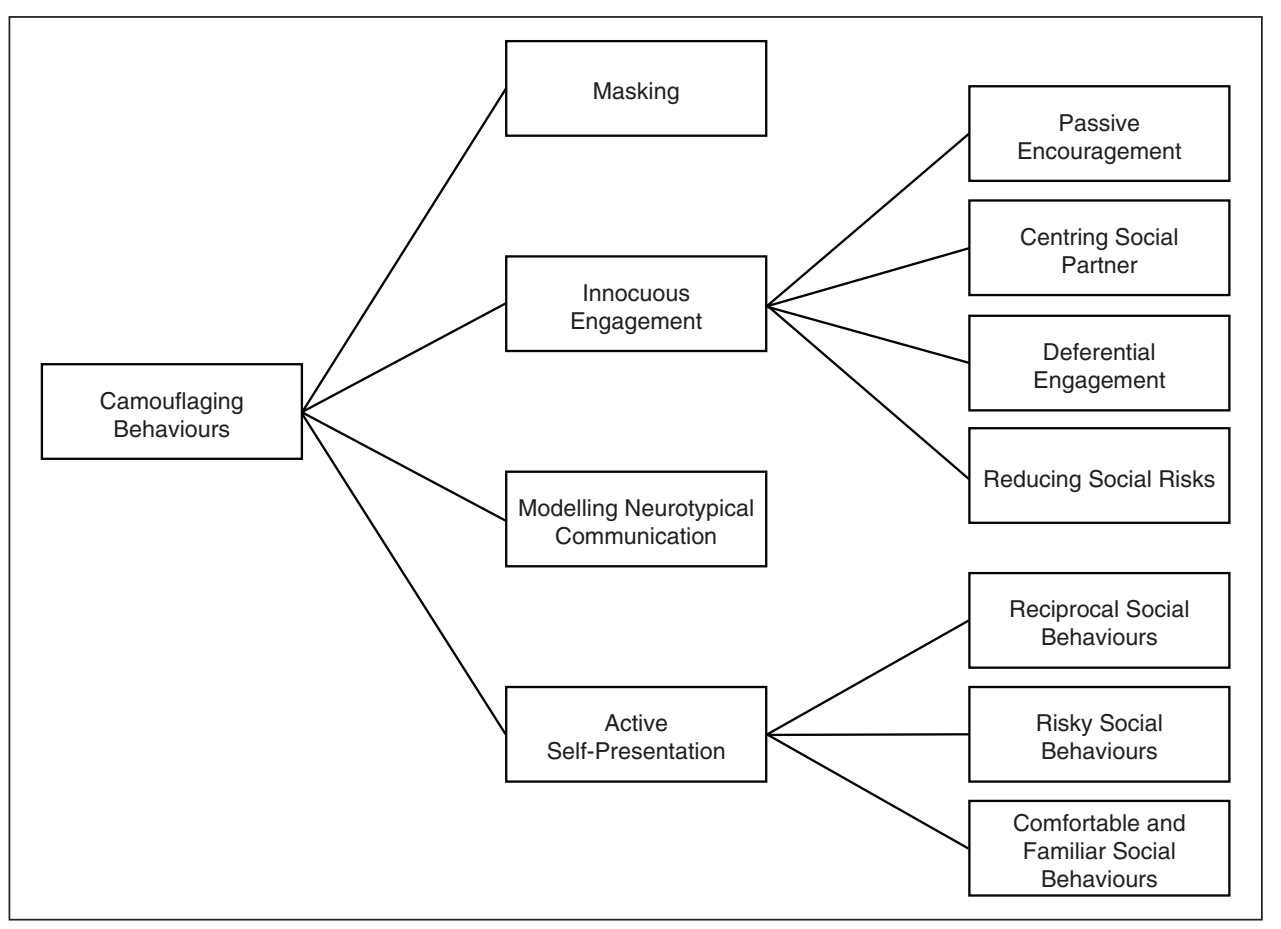

Figure I. Camouflaging behaviour categories and subcategories.

\section{Analysis}

Qualitative content analysis of interview transcripts was conducted (Elo \& Kyngäs, 2008; Graneheim \& Landman, 2004). Qualitative content analysis was chosen because it is considered to be a systematic means of describing and quantifying phenomena for the purposes of building a model or conceptual system/map (Krippendorff, 1980). Qualitative content analysis was considered more appropriate than reflective thematic analysis, previously used in camouflaging research exploring the experience of camouflaging (Hull et al., 2017; Livingston, Shah, \& Happé, 2019), given the differing focus in this study on description and quantification (Braun \& Clarke, 2019).

Qualitative content analysis was conducted following the approach described by Graneheim and Landman (2004). Analysis focused on identifying manifest (i.e. surface level) meanings in the data following an inductive approach (Elo \& Kyngäs, 2008; Kondracki, Wellman, \& Amundson, 2002). The interview transcripts were read several times by J.C. All descriptions of observable camouflaging behaviours (i.e. camouflaging behaviours participants reported engaging in during the social task and/or during other social interactions) were considered meaning units. If a behaviour was described multiple times within a single interview transcript, these descriptions were conjoined into a single meaning unit. J.C. conducted an initial coding of the interview transcripts by abstracting meaning units and labelling each with a code, reviewing and refining codes then conducting a second coding of the interview transcripts. L.H. audited the coding framework against the entire dataset. J.C. and L.H. then collaboratively reviewed and refined the framework until consensus was reached on the final codes and code frequencies. Codes (i.e. camouflaging behaviours) were then grouped into categories and subcategories on the basis of similarities and differences in interpersonal functioning. That is, similarities and differences in the manner in which behaviours may operate within an interaction to promote particular interpersonal outcomes. All authors reviewed and agreed upon the final subcategories and categories.

Note: a thematic analysis was also conducted to detail processes underlying these outward camouflaging behaviours and to capture the experience of camouflaging in autistic individuals during everyday social situations. These results are reported elsewhere (see study by Cook et al., 2021).

\section{Results}

Descriptions of behaviours exhibited, altered or avoided by participants while camouflaging were categorised into 38 codes. As detailed in Figure 1, these codes were further clustered into four main categories and seven subcategories (note: not all categories have subcategories): (1) masking; (2) innocuous engagement (subcategories: passive encouragement, centring social partner, deferential engagement and reducing social risk); (3) modelling neurotypical communication; and (4) active self-presentation 
Table 2. Description and frequencies of camouflaging codes.

\begin{tabular}{|c|c|c|}
\hline Behaviour & Description & Frequency, N (\%) \\
\hline \multicolumn{3}{|l|}{ Masking } \\
\hline $\begin{array}{l}\text { Avoid or limit discussion } \\
\text { related to oneself }\end{array}$ & $\begin{array}{l}\text { Avoiding or limiting time speaking about oneself or disclosing personal } \\
\text { information (e.g. information about one's relationship, financial status, daily } \\
\text { activities, special interests or hobbies) }\end{array}$ & II (64.7) \\
\hline $\begin{array}{l}\text { Alter or reduce hand or arm } \\
\text { movements }\end{array}$ & $\begin{array}{l}\text { Reducing the frequency or minimising the visibility of non-gesture hand } \\
\text { movements, including fidgeting movements and stimming hand movements }\end{array}$ & $8(47.1)$ \\
\hline $\begin{array}{l}\text { Avoid specific facts and } \\
\text { detailed information }\end{array}$ & Avoiding sharing factual, detailed or precise information & $7(4 \mid .2)$ \\
\hline Reduce body movements & $\begin{array}{l}\text { Reducing repetitive movements involving the torso, legs or entire body } \\
\text { including rocking and fidgeting }\end{array}$ & $3(17.6)$ \\
\hline Avoid autism & Avoiding disclosing one's autism diagnosis or discussing the topic of autism & $2(11.8)$ \\
\hline Appearance & Altering physical appearance to appear more conventional or typical & I (5.9) \\
\hline \multicolumn{3}{|l|}{ Innocuous socialising } \\
\hline \multicolumn{3}{|l|}{ Passive encouragement } \\
\hline Eye contact & $\begin{array}{l}\text { Maintaining eye contact or maintaining the appearance of eye contact (i.e. } \\
\text { looking at a social partner's forehead, nose or mouth) }\end{array}$ & II (64.7) \\
\hline Mirror & $\begin{array}{l}\text { Mirroring another person's verbal (e.g. accent) or non-verbal behaviours } \\
\text { (hand movements, body language, smile or facial expressions) }\end{array}$ & $8(47.1)$ \\
\hline Smile & Smiling at others when speaking or listening & $6(35.3)$ \\
\hline Verbal minimal encouragers & Using verbal minimal encouragers (e.g. 'oh really', 'yes', 'yeah' and 'okay') & $5(29.4)$ \\
\hline Laugh & Laughing after one's own or others' statements & $3(17.6)$ \\
\hline \multicolumn{3}{|l|}{ Centring social partner } \\
\hline Focus on social partner & $\begin{array}{l}\text { Guiding discussion to or maintaining discussion on topics of conversation } \\
\text { that are related to one's social partner or that may be of interest to one's } \\
\text { social partner }\end{array}$ & $9(52.9)$ \\
\hline $\begin{array}{l}\text { Social partner guides } \\
\text { conversation }\end{array}$ & Allowing or relying on one's social partner to guide topics of conversation & $4(23.5)$ \\
\hline \multicolumn{3}{|l|}{ Deferential engagement } \\
\hline $\begin{array}{l}\text { Apologise for/justify social } \\
\text { performance }\end{array}$ & $\begin{array}{l}\text { Apologise or provide excuses for perceived social errors or poor social } \\
\text { performance }\end{array}$ & $4(23.5)$ \\
\hline Seek approval/permission & $\begin{array}{l}\text { Seeking approval, permission or validation from one's conversational } \\
\text { partner }\end{array}$ & $4(23.5)$ \\
\hline Be cooperative & $\begin{array}{l}\text { Avoiding confrontation or complaints and/or being cooperative, respectful } \\
\text { and agreeable }\end{array}$ & $2(11.8)$ \\
\hline \multicolumn{3}{|l|}{ Reducing social risks } \\
\hline $\begin{array}{l}\text { Avoid causing offence or } \\
\text { distress }\end{array}$ & $\begin{array}{l}\text { Avoiding words or remarks that could be perceived as rude, offensive, } \\
\text { distressing or patronising }\end{array}$ & $6(35.3)$ \\
\hline Small talk & $\begin{array}{l}\text { Discussing typical 'small talk' topics such as the weather, commuting or } \\
\text { weekend activities }\end{array}$ & $6(35.3)$ \\
\hline $\begin{array}{l}\text { Avoid or limit honest, } \\
\text { direct communication }\end{array}$ & Avoiding or limiting honest or direct statements & $4(23.5)$ \\
\hline $\begin{array}{l}\text { Avoid discussion of others' } \\
\text { personal and private lives }\end{array}$ & $\begin{array}{l}\text { Avoiding questions or topics of conversation related to more personal or } \\
\text { private aspects of others' lives (e.g. relationships, social activities or general } \\
\text { life outside of work) }\end{array}$ & $4(23.5)$ \\
\hline Avoid controversy & $\begin{array}{l}\text { Avoiding or limiting discussion on topics of conversation that may generate } \\
\text { controversy or debate }\end{array}$ & $2(11.8)$ \\
\hline $\begin{array}{l}\text { Avoid appearing } \\
\text { knowledgeable }\end{array}$ & Avoiding appearing knowledgeable about specific topics or information & $2(11.8)$ \\
\hline Avoid jokes & Avoid making jokes & I (5.9) \\
\hline \multicolumn{3}{|c|}{ Modelling neurotypical communication } \\
\hline Gestures & $\begin{array}{l}\text { Altering communicative gestures so these appear more like neurotypical } \\
\text { gestures or increasing use of conventional gestures }\end{array}$ & $12(70.6)$ \\
\hline Body language & $\begin{array}{l}\text { Altering body language so this appears more like neurotypical body } \\
\text { language }\end{array}$ & $7(4 \mid .2)$ \\
\hline Clear verbal communication & $\begin{array}{l}\text { Rephrasing or slowing speech, purposefully wording comments or } \\
\text { providing clarifying comments }\end{array}$ & $7(4 \mid .2)$ \\
\hline
\end{tabular}


Table 2. (Continued)

\begin{tabular}{|c|c|c|}
\hline Behaviour & Description & Frequency, N (\%) \\
\hline Facial expressions & $\begin{array}{l}\text { Altering facial expressions so these appear more similar to neurotypical } \\
\text { facial expressions }\end{array}$ & $5(29.4)$ \\
\hline Speech intonation & $\begin{array}{l}\text { Changing the tone of one's voice or the emphasis placed on words to } \\
\text { sound more conventional or typical }\end{array}$ & $4(23.5)$ \\
\hline \multicolumn{3}{|l|}{ Active self-presentation } \\
\hline \multicolumn{3}{|l|}{ Reciprocal social behaviours } \\
\hline Ask questions & Asking one's social partner questions & $14(82.4)$ \\
\hline $\begin{array}{l}\text { Maintain and build } \\
\text { conversation }\end{array}$ & $\begin{array}{l}\text { Commenting, providing elaborating information or otherwise talking in a } \\
\text { way that builds or maintains a conversation }\end{array}$ & II (64.7) \\
\hline $\begin{array}{l}\text { Find and discuss points of } \\
\text { commonality }\end{array}$ & Establishing and discussing points of commonality with one's social partner & II (64.7) \\
\hline $\begin{array}{l}\text { Keep balance between } \\
\text { listening and talking }\end{array}$ & Keeping an even balance between talking and listening & $9(52.9)$ \\
\hline Share factual information & Sharing factual information (unrelated to oneself) with others & $7(4 \mid .2)$ \\
\hline \multicolumn{3}{|l|}{ Risky social behaviours } \\
\hline $\begin{array}{l}\text { Jokes and humorous } \\
\text { anecdotes }\end{array}$ & Making jokes or sharing humorous anecdotes & $5(29.4)$ \\
\hline $\begin{array}{l}\text { Disclose personal } \\
\text { information }\end{array}$ & $\begin{array}{l}\text { Disclosing information about ones' education, employment, daily activities } \\
\text { or relationships status }\end{array}$ & $4(23.5)$ \\
\hline Disclose weaknesses & $\begin{array}{l}\text { Discussing one's perceived weaknesses, vulnerabilities or feelings of } \\
\text { inadequacy }\end{array}$ & $2(I 1.8)$ \\
\hline \multicolumn{3}{|c|}{ Comfortable and familiar social behaviours } \\
\hline Comfortable topics & $\begin{array}{l}\text { Discussing topics of conversations that one is knowledgeable about or } \\
\text { interested in, finds easy or is comfortable discussing or have been received } \\
\text { well by others in the past }\end{array}$ & $12(70.6)$ \\
\hline Scripts & $\begin{array}{l}\text { Use an established repertoire of phrases, comments, questions or } \\
\text { anecdotes that are pre-planned or practiced, or have previously been well } \\
\text { received by others }\end{array}$ & $9(52.9)$ \\
\hline
\end{tabular}

(subcategories: reciprocal social behaviours, risky social behaviours and comfortable and familiar social behaviours). An overview of camouflaging categories and subcategories, along with the percentages of participants who reference each code (i.e. camouflaging behaviour) at least once, are described next. A full description of each of the 38 codes is provided in Table 2, while example quotes for each code are provided in the Supplementary Materials.

\section{Category I: masking}

Participants reported concealing information about their personal characteristics or circumstances and/or suppressing their innate/autistic behaviours. Participants most frequently reported avoiding or limiting personal disclosures $(\mathrm{n}=11 ; 64.7 \%)$; avoiding or suppressing autistic or otherwise atypical hand/arm movements $(\mathrm{n}=8 ; 47.1 \%)$; and avoiding sharing factual, detailed or precise information $(n=7 ; 41.2 \%)$. Some participants also described: reducing body movements $(n=3 ; 17.6 \%)$; specifically choosing not to disclose their autism diagnosis or speak about autism $(n=2 ; 11.8 \%)$; or changing their appearance $(n=1 ; 5.9 \%)$.

\section{Category 2: innocuous engagement}

Participants described using passive, cautious and/or superficial social behaviours. Many spoke of using relatively passive verbal and non-verbal social behaviours including eye contact $(n=11 ; 64.7 \%)$, mirroring $(n=8$; $47.1 \%)$, smiling $(n=6 ; 35.3 \%)$, minimal verbal encouragers $(n=5 ; 29.4 \%)$ and laughing $(n=3 ; 17.6 \%)$. Most participants also centred their social partner during interactions by guiding discussion to, or maintaining discussion on, topics related to their social partner $(n=9 ; 52.9 \%)$ or alternatively allowing their social partner to guide the conversation $(n=4 ; 23.5 \%)$. Some participants reported engaging with their social partner in a deferential manner by apologising or providing excuses for their perceived social errors or poor social performance $(n=4 ; 23.5 \%)$; seeking approval, permission or validation $(n=4 ; 23.5 \%)$; or avoiding confrontation/complaints or being cooperative/ respectful/agreeable $(n=2 ; 11.8 \%)$. Participants described avoiding social behaviours or conversational topics involving social risk. Some avoided or limited their use of honest or direct statements $(n=4 ; 23.5 \%)$. Some tried to avoid the appearance of being knowledgeable or certain about specific topics or information $(n=2 ; 11.8 \%)$. One participant 
also avoided using humour $(\mathrm{n}=1 ; 5.9 \%)$. Some participants reported keeping conversation at a superficial level by discussing traditional 'small talk' topics $(\mathrm{n}=6 ; 35.3 \%)$ while others avoided potentially controversial topics ( $\mathrm{n}=2$; $11.8 \%)$ and/or more intimate topics related to others' personal or private lives $(n=4 ; 23.5 \%)$.

\section{Category 3: modelling neurotypical communication}

Participants spoke of using specific communication behaviours in line with neurotypical norms and preferences. Many participants reported altering their communication to appear more neurotypical including altering their use of gestures $(n=12 ; 70.6 \%)$, body language $(n=7 ; 41.2 \%)$, facial expressions $(n=5 ; 29.4 \%)$ or tone of voice $(n=4$; $23.5 \%$ ). Many participants ensured their verbal communication was clear by rephrasing or slowing their speech, purposefully wording comments, or providing clarifying comments $(n=7 ; 41.2 \%)$.

\section{Category 4: active self-presentation}

Active self-presentation encompasses reciprocal, open and well-practised social behaviours. Participants described using reciprocal social behaviours involving asking questions $(\mathrm{n}=14 ; 82.4 \%)$; commenting and providing elaborating information $(\mathrm{n}=11 ; 64.7 \%)$; establishing and discussing points of similarity $(\mathrm{n}=11 ; 64.7 \%)$; keeping a balance between talking and listening $(\mathrm{n}=9 ; 52.9 \%)$; and sharing factual information $(n=7 ; 41.2 \%)$. Some participants used more risky social behaviours involving using jokes and/or humorous anecdotes $(\mathrm{n}=5 ; 29.4 \%)$, disclosing personal information $(n=4 ; 23.5 \%)$ and discussing weaknesses $(n=2$; $11.8 \%$ ). Most participants also chose conversation topics that they were comfortable discussing or knowledgeable about $(\mathrm{n}=12 ; 70.6 \%)$, as well as pre-planned or practised phrases, comments, questions or anecdotes $(n=9 ; 52.9 \%)$.

\section{Discussion}

Some autistic people modify their innate autistic social behaviour to adapt to, cope within and/or influence the predominately neurotypical social environment. In modifying their behaviour, autistic people may engage multiple cognitive functions involving monitoring the social environment, monitoring of personal behaviours (Cook et al., 2021) and social reasoning (or proxy social reasoning via non-social cognitive routes; Livingston \& Happé, 2017). However, the extent to which an autistic individual consciously engages in a process of behaviour change or is even aware of behaviour change may vary widely (Lawson, 2020).

In this study, we term such changed or modified social behaviour 'camouflaging behaviour'. With the assistance of video-cued recall, participants identified and described instances of themselves using camouflaging behaviours during a specific quasi-everyday social situation. Participants then spontaneously described additional examples of camouflaging behaviours they used in other everyday social interactions. Through this novel use of IPR methodology, we address limitations of previous qualitative research retrospectively exploring autistic people's experiences of camouflaging, days, weeks, months or even years after such experiences have occurred (e.g., Bargiela, Steward, \& Mandy, 2016; Hull et al., 2017; Livingston, Shah, \& Happé, 2019). Consequently, many of the precise and detailed descriptions of camouflaging behaviours reported in this study have not previously been documented in camouflaging research.

Camouflaging behaviours identified by participants were grouped into four categories based on the manner in which they operated within interactions: masking (i.e. hiding particular behaviours and/or aspects of one's identity); innocuous engagement (i.e. facilitating passive, cautious and superficial engagement in social interactions); neurotypical communication (i.e. communicating in line with non-autistic norms and preferences); and active selfpresentation (i.e. facilitating active, open and reciprocal participation in social interactions). We acknowledge that the categories may not necessarily be distinct, and that the use of particular strategies might relate to multiple categories at once (e.g. masking and innocuous engagement) for some individuals. Next, we examine each of these four categories of behaviours with reference to both existing camouflaging research as well as broader literature on interpersonal behaviour.

\section{Masking}

Masking involves concealing information about personal characteristics or circumstances and/or suppressing one's innate/autistic behaviours. Aspects of masking behaviours identified by participants are similar to masking strategies reported in prior camouflaging research. Specifically, camouflaging behaviours involving altering or reducing hand, arm and body movements (i.e. stimming, fidgeting, rocking) reported by our participants may be related to masking strategies involving suppressing 'atypical behaviours' on the Compensation Checklist (Livingston et al., 2020) and relaxing the face and body on the CAT-Q (Hull et al., 2019). Similarly, the camouflaging behaviour involving altering one's physical appearance identified by one participant is similar to the masking strategy involving 'superficial assimilation' on the Compensation Checklist (Livingston et al., 2020). However, other masking behaviours involving avoiding or limiting talking about oneself or disclosing personal information generally; discussing autism or one's autism diagnosis; and sharing factual, detailed or precise information were newly described in this study.

People with stigmatised identities may reduce or prevent prejudice and discrimination by hiding or minimising 
the visibility of their stigmatised characteristic (Goffman, 1963; Jones, 1984). Given that autistic people commonly experience devaluation, rejection and misunderstanding (Kinnear et al., 2016; Milton et al., 2018; Sasson et al., 2017) as well as the central role autism often plays in the identity of autistic people, it has been argued that autistic people represent an identity-based minority group subjected to social stigma and disadvantaged social status (Botha, Dibb, \& Frost, 2020; Botha \& Frost, 2020). As such, masking behaviours could be understood within a stigma framework, as an attempt to prevent prejudice and discrimination by concealing or strategically attenuating autistic identity (Botha et al., 2020; Cage \& TroxellWhitman, 2020; Pearson \& Rose, 2021; Perry et al., 2021).

Hiding personal information about oneself during a social interaction may, equally, have negative interpersonal and intrapersonal consequences. Experimental research demonstrates that hiding (versus revealing) information about a stigmatised characteristic during an interaction is associated with reduced non-stigma-related self-disclosure and, in turn, external observers rate individuals and their interactions less positively (Newheiser \& Barreto, 2014). Moreover, for the stigmatised individual, actively concealing stigma-related information is associated with decreased cognitive resources (Critcher \& Ferguson, 2014; Smart \& Wegner, 1999), decreased feelings of belonging and authenticity (Newheiser \& Barreto, 2014) and increased emotional strain (Barreto, Ellemers, \& Banal, 2006).

Research in the field of social anxiety similarly demonstrates the negative intra and interpersonal consequences associated with hiding aspects of the self during social interactions. Socially anxious individuals attempt to prevent feared negative evaluations or social outcomes by engaging in 'safety behaviours' (Rapee \& Heimberg, 1997). Some of these safety behaviours involve hiding aspects of the self through, for example, avoiding talking about oneself, asking questions or talking altogether; censoring one's speech; trying not to attract attention; or keeping still (Gray, Beierl, \& Clark, 2019; Hirsch, Meynen, \& Clark, 2004; Plasencia et al., 2011). Experimental research suggests conversational partners and independent observers rate individuals engaging in hiding behaviours as more anxious, less likeable, less enjoyable to interact with and less desirable as a future social partner compared to controls (Gray et al., 2019; Plasencia et al., 2011). In terms of intra-personal costs, use of safety behaviours including hiding/avoidance behaviours is also associated with increased anxiety and belief in social fears, as well as poorer self-reported perception of social performance (McManus, Sacadura, \& Clark, 2008).

\section{Innocuous engagement}

Innocuous engagement behaviours (encompassing passive encouragement, centring social partner, deferential engagement and reducing social risks) are more cautious, passive and superficial social behaviours. These behaviours facilitate surface-level engagement in social interactions and centre autistic people's social partners by prioritising their enjoyment, comfort and preferences. At the same time, these behaviours minimise the likelihood of controversy, disagreement and negative evaluation. Aspects of passive encouragement and centring social partner behaviours described by participants are reflected in masking and shallow compensation strategies in the Compensation Checklist (Livingston et al., 2020) as well as masking and compensation strategies in the CAT-Q (Hull et al., 2019). However, the specific passive encouragement behaviours involving using laughter and minimal encouragers are newly identified by participants in this study. Similarly, most camouflaging behaviours involving deferential engagement (i.e. justifying, apologising and seeking permission) and minimising social risks (i.e. avoiding controversy, direct communication, discussing others' personal lives, humour etc.), reported by participants in this study, have not previously been reported within camouflaging research.

Innocuous engagement behaviours are conceptually similar to another category of safety behaviours used by socially anxious individuals involving 'innocuous sociability' (Leary, 1995; Schlenker \& Leary, 1982). Innocuous sociability involves a self-protective interpersonal style characterised by safe and innocuous social behaviours (e.g. engaging in more smiling, nodding and minimal verbal acknowledgements; asking more questions; avoiding interrupting others; and making less factual statements; Leary, Knight, \& Johnson, 1987; Leary \& JongmanSereno, 2014; Leary \& Kowalski, 1995b; Patterson \& Ritts, 1997). These behaviours serve to keep an individual engaged in an interaction while simultaneously shifting focus away from them and minimising risks to their image. It is suggested that in the case of social anxiety, this interpersonal style may protect an individual from blatant negative evaluation but at the same time is unlikely to result in a particularly positive social impression (Leary \& Jongman-Sereno, 2014).

Innocuous engagement involving excessive accommodation of others' enjoyment, comfort and preferences may, however, be associated with harmful interpersonal consequences. In the non-autistic population, unassertive and submissive interpersonal behaviours are consistently linked to negative outcomes across the lifespan, including increased social isolation (Rubin \& Burgess, 2001), workplace bullying (e.g. Zapf \& Einarsen, 2003) and sexual assault (Ullman, 2007). Little research exists examining links between interpersonal style and outcomes for autistic people. However, in a small qualitative study involving late diagnosed autistic women, participants linked their perceived passivity, social mimicry and prioritisation of fitting in over their own needs to experiences of abuse and 
victimisation (Bargiela et al., 2016). This potential link is of significant concern given recent discussion regarding the role of autism interventions in fostering overly compliant behaviour in autistic people (Sandoval-Norton \& Shkedy, 2019).

\section{Modelling neurotypical communication}

Modelling neurotypical communication behaviours identified by participants involved altering verbal and nonverbal communication so as to conform with neurotypical conventions and preferences. Similar examples of autistic people copying or mimicking the verbal and non-verbal communication behaviours of neurotypical others are found throughout camouflaging literature (e.g. Cridland et al., 2014; Hull et al., 2019; Livingston, Shah, \& Happé, 2019).

In a similar manner to masking behaviours, modelling neurotypical communication behaviours could be understood within a stigma framework as an attempt to reduce prejudice or discrimination by signalling proximity to neurotypicality (Pearson \& Rose, 2021; Perry, Mandy, Hull, \& Cage, 2021). In addition, using the normative expressions of the culture, subculture or family one is interacting with likely improves clarity and ease in communication (Halberstadt, Denham, \& Dunsmore, 2001). Given the difficulties non-autistic people experience identifying and understanding autistic social communication, autistic people using more neurotypical communication behaviours may be more readily understood during everyday social encounters (Jaswal \& Akhtar, 2019; Sheppard et al., 2016). Likewise, as non-autistic people often perceive neurotypical social communication behaviour as communicating social motivation, they may engage more with autistic people exhibiting such behaviour (Jaswal \& Akhtar, 2019).

\section{Active self-presentation}

The active self-presentation behaviours (including reciprocal, risky and comfortable and familiar social behaviours) described by participants appear to directly influence interpersonal elements of social interactions. Reciprocal behaviours initiate, build and maintain interpersonal exchanges within interactions. Reciprocity is further facilitated by the use of accessible, comfortable, pre-planned or practised phrases, questions, anecdotes or conversational topics as well as humour and exchange of personal information.

The comfortable and familiar social behaviours reported by participants appear to be related to shallow compensation strategies in the Compensation Checklist (Livingston et al., 2020) and compensation strategies in the CAT-Q (Hull et al., 2019). However, behaviours reported by participants involving reciprocal, authentic and open engagement (e.g. maintaining and building conversation; finding and discussing points of commonality; disclosing personal information; using humour etc.) are similar to behaviours typically described within research with non-autistic people as socially skillful behaviours.

Considerable research suggests perceived similarity with a social partner in terms of, for example, attitudes, personality traits and hobbies, is strongly associated with increased feelings of liking and/or attraction for that social partner (e.g. Hampton, Fisher Boyd, \& Sprecher, 2019; Montoya, Horton, \& Kirchner, 2008). For non-autistic people, self-disclosure appears to facilitate perceived similarity (Collins \& Miller, 1994; Laurenceau, Barrett, \& Pietromonaco, 1998; Sprecher, 2014). In the case of camouflaging, autistic people's attempts to adapt their interpersonal style by concealing autistic behaviours, engaging in neurotypical social niceties and exhibiting non-autistic social communication (i.e. masking, innocuous engagement and neurotypical communication behaviours) may signal a level of similarity to non-autistic social partners. However, active self-presentation behaviours involving disclosing personal information, as well as actively searching for and exploring commonalities, are likely more effective in establishing similarities with non-autistic social partners on the key dimensions of attitudes, personality traits and hobbies and, in turn, more successful in building mutual admiration and understanding.

For non-autistic people, responsiveness to others' disclosures during an interaction is also associated with positive perceptions and social relatedness (Butler et al., 2003; Forest \& Wood, 2011). As such, active self-presentation camouflaging behaviours focused on maintaining reciprocity during an interaction may also foster positive reactions and behaviours from non-autistic social partners. At the same time, compared to other camouflaging behaviours, active self-presentation behaviours involving disclosing personal information, responding to others, sharing opinions and using humour involve an element of social risk. Thus, if unsuccessfully deployed, they may increase the likelihood of negative evaluation.

In line with previous literature (Fombonne, 2020; Lai et al., 2021; Schneid \& Raz, 2020), the above discussion highlights that some of the camouflaging behaviours described by autistic people may be similar to social behaviours observed in non-autistic people. Self-presentation explanations of interpersonal behaviour may provide a framework through which we can understand commonalities and differences in the social behaviours of autistic and non-autistic people. Self-presentation approaches posit that people are generally motivated to make desirable social impressions and avoid undesirable social impressions because they are rewarded, via the positive reactions and treatment of others, for doing so (Leary, 1995; Schlenker, 1980; Schlenker \& Leary, 1982). In promoting a desirable social impression, people (1) exhibit behaviours they believe will lead others to perceive them in a desirable 
manner, (2) monitor others' reactions to these behaviours and (3) strategically adjust their behaviour when they believe others are perceiving them in an undesirable manner (Leary, 1995). People experience anxiety when they are motivated to make a desirable social impression, but they doubt their ability to do so (Leary \& Kowalski, 1995a; 1995b; Schlenker \& Leary, 1982). Furthermore, people who believe that others consistently form undesirable impressions of them develop and utilise additional repertoires of interpersonal behaviours to minimise the impact of anticipated threats to achieving desirable social impressions. People with stigmatised identities who believe that others form undesirable impressions of them because they possess a particular stigmatised characteristic may develop similar repertoires of self-presentational behaviours to minimise the impact of their stigmatised characteristic on others' perceptions of them (Miller \& Kaiser, 2006). Socially anxious people who perceive that others form undesirable impressions of them may similarly utilise specific selfpresentational behaviours to protect or enhance their social impression (Leary \& Jongman-Sereno, 2014). There are both individual differences and group-level similarities in these repertoires of interpersonal behaviours. Through this framework, camouflaging could be conceptualised as a repertoire of self-presentational behaviours used by autistic people to achieve a desirable social image and promote positive reactions from others.

Self-presentation approaches further suggest that while the specific type of desirable social impression an individual is motivated to convey can vary, such motivations are heavily influenced by social context. People generally wish to make common types of desirable impressions (e.g. as friendly, competent, ethical, attractive etc.) and avoid other common types of undesirable impressions (e.g. as unfriendly, incompetent, unethical, unattractive etc.; Leary, 1995). In this regard, autistic and non-autistic people existing within a predominately neurotypical social context are likely motivated to make similar neurotypical desirable impressions and avoid similar neurotypical undesirable impressions because they are similarly rewarded by the reactions and treatment of others for doing so. Thus, a degree of overlap is to be expected in the type of self-presentation behaviours utilised by autistic and non-autistic people in achieving desirable impressions as well as those used by autistic, other stigmatised and socially anxious individuals in avoiding anticipated undesirable impressions.

At the same time, some camouflaging behaviours are unique to autism because they minimise autism-specific threats to creating a desirable impression (e.g. hand flapping may represent an autism-specific threat to being perceived as competent). Similarly, the cognitive processes used by autistic and non-autistic people to produce similar self-presentation behaviours may vary, for example, nonautistic people may utilise social reasoning while autistic people may utilise proxy social reasoning via non-social cognitive routes (Livingston \& Happé, 2017). Equally, some camouflaging behaviours are unique to individuals because they minimise more individualistic threats to creating a desirable impression (i.e. they are developed in response to idiosyncratic social experiences, reasoning or beliefs) or they represent individualistic solutions to minimising common group-level threats.

Furthermore, according to the self-presentation framework, people commonly experience anxiety when they are motivated to make a desirable social impression, but they doubt they will successfully be able to do so (Leary \& Jongman-Sereno, 2014). Thus, autistic and other stigmatised people (as well as those with social anxiety disorder) may similarly experience heightened social anxiety if they believe they are unable to make desirable impressions. Autistic and other stigmatised people who believe they can successfully reduce threats to achieving a desirable social impression by using a repertoire of self-presentational behaviours will experience less anxiety compared to those who use similar behaviours yet remain uncertain or doubtful.

Within research involving non-autistic people, distinct subtypes of interpersonal behaviours are associated with different interpersonal and intra-personal consequences. The effect of camouflaging behaviours on interpersonal outcomes, whether beneficial or harmful, is dependent on the way these behaviours are implemented. In this regard, there are likely qualitative differences in the manner in which autistic and non-autistic people exhibit similar social behaviours. Equally, how autistic people employ specific camouflaging behaviours during social interactions is likely to vary widely in accordance with differences in gender, age, social experiences and various cognitive abilities. Furthermore, the intrapersonal consequences of various social behaviours may be dissimilar for autistic and nonautistic people, due to differences in the origins and functions of such behaviours as well as the cognitive functions that produce them. Relatedly, the findings reported here and elsewhere in camouflaging research suggest autistic individuals use a diverse range of camouflaging behaviours to cope and succeed in social interactions (Hull et al., 2017; Livingston, Shah, \& Happé, 2019). It remains unclear to what extent specific camouflaging and/or social behaviours differentially facilitate, social, functional or mental health outcomes within the autistic population.

As reiterated in recent editorials on the subject, conceptualisations, definitions and measures of camouflaging are in their infancy (Fombonne, 2020; Lai et al., 2021). This study contributes to our understanding of camouflaging by generating specific and detailed descriptions of self-reported camouflaging behaviours and discussing potential similarities between these and various other social behaviours. Further research directly comparing social behaviours reported by autistic and non-autistic people is now needed to better delineate neurotype general versus neurotype-specific 
components of camouflaging. Experimental research is also needed to better understand the in situ influence of camouflaging behaviours in relation to both non-autistic people's evaluation and treatment of autistic people as well as autistic people's cognitive resources and psychological distress.

Future research examining autistic people's experiences of socialising during cross-neurotype interactions will likely benefit from examining a wider range of social behaviours than is currently documented in camouflaging research. Indeed, while most often defined in research as the use of strategies to hide and or compensate for autistic characteristics (Hull et al., 2017, 2019, 2020; Lai et al., 2011), when asked to identify their camouflaging behaviours, some participants in this study reported using autistic strengths (i.e. sharing factual information) as well as unfiltered, open and 'skilful' social behaviours (i.e. disclosing personal information, discussing points of commonality and using humour). Similarly, autistic scholars have criticised interpretations and explanations of camouflaging behaviours presented throughout previous camouflaging research (Lawson, 2020; Schneid \& Raz, 2020). As such, the adoption of more general language and terminology (i.e. social behaviours or coping strategies rather than camouflaging behaviours) may aid in illuminating additional perspectives.

It is important to acknowledge that, given the methodology utilised, the results may not generalise to all social environments or autistic individuals. Individuals' social behaviours are influenced by their immediate social context and in this regard the camouflaging behaviours reported by participants were likely impacted by non-naturalistic features of the lab-based environment, such as participants' awareness that they were taking part in a study about camouflaging. Equally, IPR interviews explore conscious experience and thus cannot identify camouflaging behaviours operating outside of conscious awareness. IPR is only suitable for use with verbally fluent individuals who have a relatively high level of insight into their camouflaging behaviours. Given all our participants were verbally fluent and had intellectual abilities in the average to high average range, the camouflaging behaviours reported in this study may not be representative of all camouflaging behaviours utilised by the full spectrum of autistic people. Furthermore, although the use of self-report methodology went some way in reducing the influence of neurotypical conceptualisations and biases in describing camouflaging, our methodology is limited by a lack of autistic input with regard to design and analysis.

This study identifies and describes camouflaging behaviours used by a sample of autistic adults in everyday social interactions. Participants' descriptions of camouflaging behaviours suggest some camouflaging behaviours may be common to both autistic and non-autistic socialising while others are unique to autistic socialising. Camouflaging-type behaviours may be similarly used by autistic and non-autistic people to make desired social impressions and elicit positive reactions and treatment from others. For non-autistic people, distinct subtypes of interpersonal behaviours are associated with different interpersonal and intra-personal consequences. Future research is needed to examine if various camouflaging behaviours differentially facilitate outcomes for autistic people.

\section{Acknowledgements}

We thank Tony Attwood for his advice in conceptualising the study.

\section{Declaration of conflicting interests}

The author(s) declared no potential conflicts of interest with respect to the research, authorship, and/or publication of this article.

\section{Funding}

The author(s) disclosed receipt of the following financial support for the research, authorship, and/or publication of this article: J.C. is funded by a doctoral scholarship from the University College of London.

\section{ORCID iDs}

Julia Cook (iD) https://orcid.org/0000-0002-8984-6656

Laura Crane (iD https://orcid.org/0000-0002-4161-3490

Laura Hull iD https://orcid.org/0000-0002-8289-2158

William Mandy (iD) https://orcid.org/0000-0002-3564-5808

\section{Supplemental material}

Supplemental material for this article is available online.

\section{References}

American Psychiatric Association. (2013). Diagnostic and statistical manual of mental disorders (5th ed.).

Bargiela, S., Steward, R., \& Mandy, W. (2016). The experiences of late-diagnosed women with autism spectrum conditions: An investigation of the female autism phenotype. Journal of Autism and Developmental Disorders, 46(10), 3281-3294.

Baron-Cohen, S., Jolliffe, T., Mortimore, C., \& Robertson, M. (1997). Another advanced test of theory of mind: Evidence from very high functioning adults with autism or Asperger syndrome. Journal of Child Psychology and Psychiatry, 38(7), 813-822.

Baron-Cohen, S., Wheelwright, S., Skinner, R., Martin, J., \& Clubley, E. (2001). The autism-spectrum quotient (AQ): Evidence from Asperger syndrome/high-functioning autism, males and females, scientists and mathematicians. Journal of Autism and Developmental Disorders, 31(1), 5-17.

Barreto, M., Ellemers, N., \& Banal, S. (2006). Working under cover: Performance-related self-confidence among members of contextually devalued groups who try to pass. European Journal of Social Psychology, 36(3), 337-352. 
Bartz, R. (1999). Beyond the biopsychosocial model. The Journal of Family Practice, 48(8), 60.

Beck, J. S., Lundwall, R. A., Gabrielsen, T., Cox, J. C., \& South, M. (2020). Looking good but feeling bad: "Camouflaging" behaviors and mental health in women with autistic traits. Autism, 24(4), 809-821.

Billstedt, E., Gillberg, I. C., \& Gillberg, C. (2011). Aspects of quality of life in adults diagnosed with autism in childhood: A population-based study. Autism, 15(1), 7-20.

Botha, M., Dibb, B., \& Frost, D. M. (2020). 'Autism is me': An investigation of how autistic individuals make sense of autism and stigma. Disability \& Society, 1-27. https://10.1080/0968 7599.2020 .1822782

Botha, M., \& Frost, D. M. (2020). Extending the minority stress model to understand mental health problems experienced by the autistic population. Society and Mental Health, 10(1), 20-34.

Braun, V., \& Clarke, V. (2019). Novel insights into patients' life-worlds: The value of qualitative research. The Lancet Psychiatry, 6(9), 720-721.

Burgess, S., Rhodes, P., \& Wilson, V. (2013). Exploring the insession reflective capacity of clinical psychology trainees: An interpersonal process recall study. Clinical Psychologist, 17(3), 122-130.

Butler, E. A., Egloff, B., Wilhelm, F. H., Smith, N. C., Erickson, E. A., \& Gross, J. J. (2003). The social consequences of expressive suppression. Emotion, 3, 48-67.

Cage, E., \& Troxell-Whitman, Z. (2019). Understanding the reasons, contexts and costs of camouflaging for autistic adults. Journal of Autism and Developmental Disorders, 49(5).

Cage, E., \& Troxell-Whitman, Z. (2020). Understanding the relationships between autistic identity, disclosure, and camouflaging. Autism in Adulthood, 2(4), 334-338.

Campbell, J. M., Ferguson, J. E., Herzinger, C. V., Jackson, J. N., $\&$ Marino, C. A. (2004). Combined descriptive and explanatory information improves peers' perceptions of autism. Research in Developmental Disabilities, 25(4), 321-339.

Cassidy, S. A., Gould, K., Townsend, E., Pelton, M., Robertson, A. E., \& Rodgers, J. (2019). Is camouflaging autistic traits associated with suicidal thoughts and behaviours? Expanding the interpersonal psychological theory of suicide in an undergraduate student sample. Journal of Autism and Developmental Disorders, 50, 3638-3648.

Collins, N. L., \& Miller, L. C. (1994). Self-disclosure and liking: A meta-analytic review. Psychological Bulletin, 116, 457-475.

Corbett, B. A., Schwartzman, J. M., Libsack, E. J., Muscatello, R. A., Lerner, M. D., Simmons, G. L., \& White, S. W. (2021). Camouflaging in Autism: Examining sex-based and compensatory models in social cognition and communication. Autism Research, 14(1), 127-142.

Cook, J., Crane, L., Bourne, L., Hull, L., \& Mandy, W. (2021). Camouflaging in an everyday social context: An interpersonal recall study. Autism, 1-13. https://doi. org/10.1177/1362361321992641

Cridland, E. K., Jones, S. C., Caputi, P., \& Magee, C. A. (2014). Being a girl in a boys' world: Investigating the experiences of girls with autism spectrum disorders during adolescence. Journal of Autism and Developmental Disorders, 44(6), $1261-1274$
Critcher, C. R., \& Ferguson, M. J. (2014). The cost of keeping it hidden: Decomposing concealment reveals what makes it depleting. Journal of Experimental Psychology: General, 143(2), 721-735.

Crompton, C. J., Ropar, D., Evans-Williams, C. V., Flynn, E. G., \& Fletcher-Watson, S. (2020). Autistic peer-to-peer information transfer is highly effective. Autism, 24, 1704-1712.

Cuddy, A. J., Fiske, S. T., \& Glick, P. (2008). Warmth and competence as universal dimensions of social perception: The stereotype content model and the BIAS map. Advances in Experimental Social Psychology, 40, 61-149.

Dean, M., Harwood, R., \& Kasari, C. (2017). The art of camouflage: Gender differences in the social behaviors of girls and boys with autism spectrum disorder. Autism, 21(6), 678-689.

De Jaegher, H. (2013). Embodiment and sense-making in autism. Frontiers in Integrative Neuroscience, 7, 15.

de Marchena, A., \& Eigsti, I. M. (2010). Conversational gestures in autism spectrum disorders: Asynchrony but not decreased frequency. Autism Research, 3(6), 311-322.

de Villiers, J., Fine, J., Ginsberg, G., Vaccarella, L., \& Szatmari, P. (2007). Brief report: A scale for rating conversational impairment in autism spectrum disorder. Journal of Autism and Developmental Disorders, 37(7), 1375-1380.

Edey, R., Cook, J., Brewer, R., Johnson, M. H., Bird, G., \& Press, C. (2016). Interaction takes two: Typical adults exhibit mind-blindness towards those with autism spectrum disorder. Journal of Abnormal Psychology, 125(7), 879.

Elo, S., \& Kyngäs, H. (2008). The qualitative content analysis process. Journal of Advanced Nursing, 62(1), 107-115.

Faso, D. J., Sasson, N. J., \& Pinkham, A. E. (2015). Evaluating posed and evoked facial expressions of emotion from adults with autism spectrum disorder. Journal of Autism and Developmental Disorders, 45(1), 75-89.

Fombonne, E. (2020). Camouflage and autism. Journal of Child Psychology and Psychiatry, 61, 735-738.

Forest, A. L., \& Wood, J. V. (2011). When partner caring leads to sharing: Partner responsiveness increases expressivity, but only for individuals with low self-esteem. Journal of Experimental Social Psychology, 47, 843-848.

Forgeot d'Arc, B. F., \& Soulières, I. (2019). Socially interested, or socially sophisticated? On mutual social influence in autism. Behavioral and Brain Sciences, 42, e89.

Frith, U., \& Happé, F. (1994). Autism: Beyond 'theory of mind'. Cognition, 50(1), 115-132.

Goffman, E. (1963). Stigma: Notes on the management of spoiled identity. Prentice-Hall.

Graneheim, U. H., \& Lundman, B. (2004). Qualitative content analysis in nursing research: Concepts, procedures and measures to achieve trustworthiness. Nurse Education Today, 24(2), 105-112.

Gray, E., Beierl, E. T., \& Clark, D. M. (2019). Sub-types of safety behaviours and their effects on social anxiety disorder. PLOS ONE, 14(10), Article e0223165.

Halberstadt, A. G., Denham, S. A., \& Dunsmore, J. C. (2001). Affective social competence. Social Development, 10, 79119.

Hampton, A. J., Fisher Boyd, A. N., \& Sprecher, S. (2019). You're like me and I like you: Mediators of the similarity-liking link assessed before and after a getting-acquainted social 
interaction. Journal of Social and Personal Relationships, 36(7), 2221-2244.

Hirsch, C., Meynen, T., \& Clark, D. (2004). Negative selfimagery in social anxiety contaminates social interactions. Memory, 12(4), 496-506.

Howlin, P., Goode, S., Hutton, J., \& Rutter, M. (2004). Adult outcome for children with autism. Journal of Child Psychology and Psychiatry, 45(2). 212-229.

Huang, K., Yeomans, M., Brooks, A. W., Minson, J., \& Gino, F. (2017). It doesn't hurt to ask: Question-asking increases liking. Journal of Personality and Social Psychology, 113(3), 430-452.

Hull, L., Lai, M. C., Baron-Cohen, S., Allison, C., Smith, P., Petrides, K. V., \& Mandy, W. (2020). Gender differences in self-reported camouflaging in autistic and non-autistic adults. Autism, 24(2), 352-363.

Hull, L., Levy, L., Lai, M. C., Petrides, K. V., Baron-Cohen, S., Allison, C., . . \& \& Mandy, W. (2021). Is social camouflaging associated with anxiety and depression in autistic adults? Molecular Autism, 12(1), 1-13.

Hull, L., Mandy, W., Lai, M. C., Baron-Cohen, S., Allison, C., Smith, P., \& Petrides, K. V. (2019). Development and validation of the camouflaging autistic traits questionnaire (CAT-Q). Journal of Autism and Developmental Disorders, 49(3), 819-833.

Hull, L., Petrides, K. V., Allison, C., Smith, P., Baron-Cohen, S., Lai, M. C., \& Mandy, W. (2017). 'Putting on my best normal': Social camouflaging in adults with autism spectrum conditions. Journal of Autism and Developmental Disorders, 47(8), 2519-2534.

Inderbitzen-Nolan, H. M., Anderson, E. R., \& Johnson, H. S. (2007). Subjective versus objective behavioral ratings following two analogue tasks: A comparison of socially phobic and non-anxious adolescents. Journal of Anxiety Disorders, 21(1), 76-90.

Jaswal, V. K., \& Akhtar, N. (2019). Being versus appearing socially uninterested: Challenging assumptions about social motivation in autism. Behavioral and Brain Sciences, 42, e82.

Jones, E. (1984). Social stigma: The psychology of marked relationships. WH Freeman.

Kagan, N., Schauble, P., Resnikoff, A., Danish, S. J., \& Krathwohl, D. R. (1969). Interpersonal process recall. Journal of Nervous and Mental Disease, 148(4), 365-374.

Kinnear, S. H., Link, B. G., Ballan, M. S., \& Fischbach, R. L. (2016). Understanding the experience of stigma for parents of children with autism spectrum disorder and the role stigma plays in families' lives. Journal of Autism and Developmental Disorders, 46(3), 942-953.

Kondracki, N. L., Wellman, N. S., \& Amundson, D. R. (2002). Content analysis: Review of methods and their applications in nutrition education. Journal of Nutrition Education and Behavior, 34(4), 224-230.

Krippendorff, K. (1980). Content analysis: An introduction to its methodology. SAGE.

Lai, M. C., Hull, L., Mandy, W., Chakrabarti, B., Nordahl, C. W., Lombardo, M. V., Ameis, S. H., Szatmari, P., BaronCohen, S., Happé, F., \& Livingston, L. A. (2021). Commentary: 'Camouflaging' in autistic people - reflection on Fombonne (2020). Journal of Child Psychology and Psychiatry. Advance online publication. https://doi.org/10.1111/jcpp.13344
Lai, M. C., Lombardo, M. V., Chakrabarti, B., Ruigrok, A. N., Bullmore, E. T., Suckling, J., . . \& \& Baron-Cohen, S. (2019). Neural self-representation in autistic women and association with 'compensatory camouflaging'. Autism, 23(5), $1210-1223$.

Lai, M. C., Lombardo, M. V., Pasco, G., Ruigrok, A. N., Wheelwright, S. J., Sadek, S. A., . . . \& MRC AIMS Consortium. (2011). A behavioral comparison of male and female adults with high functioning autism spectrum conditions. PloS One, 6(6), e20835.

Lai, M. C., Lombardo, M. V., Ruigrok, A. N., Chakrabarti, B., Auyeung, B., Szatmari, P., Happé, F., \& Baron-Cohen, S., \& MRC AIMS Consortium. (2017). Quantifying and exploring camouflaging in men and women with autism. Autism, 21(6), 690-702.

Larsen, D., Flesaker, K., \& Stege, R. (2008). Qualitative interviewing using interpersonal process recall: Investigating internal experiences during professional-client conversations. International Journal of Qualitative Methods, 7(1), $18-37$.

Laurenceau, J.-P., Barrett, L. F., \& Pietromonaco, P. R. (1998). Intimacy as an interpersonal process: The importance of self-disclosure, partner disclosure, and perceived partner responsiveness in interpersonal exchanges. Journal of Personality and Social Psychology, 74, 1238-1251.

Lawson, W. (2020). Adaptive morphing and coping with social threat in autism: An autistic perspective. Journal of Intellectual Disability Diagnosis and Treatment, 8(3), 519-526.

Leary, M. R. (1995). Self-presentation: Impression management and interpersonal behaviour. Brown and Benchmark. https://doi.org/10.4324/9780429497384

Leary, M. R., \& Jongman-Sereno, K. (2014). Social anxiety as an early warning system: A refinement and extension of the self-presentation theory of social anxiety. In S. Hofmann \& P. DiBartolo (Eds.), Social anxiety: Clinical, developmental, and social perspectives (3rd ed., pp. 579597). Elsevier.

Leary, M. R., Knight, P. D., \& Johnson, K. A. (1987). Social anxiety and dyadic conversation: A verbal response analysis. Journal of Social and Clinical Psychology, 5(1), 34-50.

Leary, M. R., \& Kowalski, R. M. (1995a). The self-presentation model of social phobia. In R. G. Heimberg, M. R. Liebowitz, D. A. Hope, \& F. R. Schneier (Eds.), Social phobia: Diagnosis, assessment, and treatment (pp. 94-112). Guilford Press.

Leary, M. R., \& Kowalski, R. M. (1995b). Social anxiety. Guilford Press.

Lever, A. G., \& Geurts, H. M. (2016). Psychiatric co-occurring symptoms and disorders in young, middle-aged, and older adults with autism spectrum disorder. Journal of Autism and Developmental Disorders, 46(6), 1916-1930.

Livingston, L. A., \& Colvert, E. Social Relationships Study Team Bolton, P., \& Happé, F. (2019). Good social skills despite poor theory of mind: Exploring compensation in autism spectrum disorder. Journal of Child Psychology and Psychiatry, 60(1), 102-110.

Livingston, L. A., \& Happé, F. (2017). Conceptualising compensation in neurodevelopmental disorders: Reflections from 
autism spectrum disorder. Neuroscience \& Biobehavioral Reviews, 80, 729-742.

Livingston, L. A., Shah, P., \& Happé, F. (2019). Compensatory strategies below the behavioural surface in autism: A qualitative study. The Lancet Psychiatry, 6(9), 766-777.

Livingston, L. A., Shah, P., Milner, V., \& Happé, F. (2020). Quantifying compensatory strategies in adults with and without diagnosed autism. Molecular Autism, 11(1), Article 15.

Marsh, J. (1983). The boredom of study: A study of boredom. Management Education \& Development, 14, 120-135.

McManus, F., Sacadura, C., \& Clark, D. M. (2008). Why social anxiety persists: An experimental investigation of the role of safety behaviours as a maintaining factor. Journal of Behavior Therapy and Experimental Psychiatry, 39(2), 147-161.

Miller, C., \& Kaiser, C. (2006). Implications of mental models of self and others for the targets of stigmatization. In M. R. Leary (Ed.), Interpersonal rejection (pp. 189-212). Oxford University Press.

Milton, D. (2012). On the ontological status of autism: The 'double empathy problem'. Disability \& Society, 27(6), 883-887.

Milton, D., Heasman, B., \& Sheppard, E. (2018). Double empathy. In F. R. Volkmar (Ed.), Encylopedia of autism spectrum disorders (pp. 1-8). Springer.

Montoya, R. M., Horton, R. S., \& Kirchner, J. (2008). Is actual similarity necessary for attraction? A meta-analysis of actual and perceived similarity. Journal of Social and Personal Relationships, 25(6), 889-922.

Morrison, K. E., DeBrabander, K. M., Faso, D. J., \& Sasson, N. J. (2019). Variability in first impressions of autistic adults made by neurotypical raters is driven more by characteristics of the rater than by characteristics of autistic adults. Autism, 23(7), 1817-1829.

Newheiser, A. K., \& Barreto, M. (2014). Hidden costs of hiding stigma: Ironic interpersonal consequences of concealing a stigmatized identity in social interactions. Journal of Experimental Social Psychology, 52, 58-70.

Nicolaidis, C., Raymaker, D., Kapp, S. K., Baggs, A., Ashkenazy, E., McDonald, K., Weiner, M., Maslak, J., Hunter, M., \& Joyce, A. (2019). The AASPIRE practice-based guidelines for the inclusion of autistic adults in research as co-researchers and study participants. Autism, 23(8), 2007-2019.

Omodei, M. M., \& McLennan, J. (1994). Studying complex decision making in natural settings: Using a head-mounted video camera to study competitive orienteering. Perceptual and Motor Skills, 79(3), 1411-1425.

Omodei, M. M., McLennan, J., \& Wearing, A. J. (2005). How expertise is applied in real-world dynamic environments: Head mounted video and cued recall as a methodology for studying routines of decision making. In T. Betsch \& $\mathrm{S}$. Haberstroh (Eds.), The routines of decision making (pp. 271-288). Lawrence Erlbaum Associates.

Orsmond, G. I., Shattuck, P. T., Cooper, B. P., Sterzing, P. R., \& Anderson, K. A. (2013). Social participation among young adults with an autism spectrum disorder. Journal of Autism and Developmental Disorders, 43(11), 2710-2719.

Papagiannopoulou, E. A., Chitty, K. M., Hermens, D. F., Hickie, I. B., \& Lagopoulos, J. (2014). A systematic review and meta-analysis of eye-tracking studies in children with autism spectrum disorders. Social Neuroscience, 9(6), 610-632.
Patterson, M. L., \& Ritts, V. (1997). Social and communicative anxiety: A review and meta-analysis. Annals of the International Communication Association, 20(1), 263303.

Pearson, A., \& Rose, K. (2021). A conceptual analysis of autistic masking: Understanding the narrative of stigma and the illusion of choice. Autism in Adulthood, 3(1), 52-60.

Perry, E., Mandy, W., Hull, L., \& Cage, E. (2021). Understanding camouflaging as a response to autism-related stigma: A Social Identity Theory approach. Journal of Autism and Developmental Disorders. Advance online publication. https://doi.org/10.1007/s10803-021-04987-w

Plasencia, M. L., Alden, L. E., \& Taylor, C. T. (2011). Differential effects of safety behaviour subtypes in social anxiety disorder. Behaviour Research and Therapy, 49(10), 665-675.

Rapee, R. M., \& Heimberg, R. G. (1997). A cognitive-behavioral model of anxiety in social phobia. Behaviour Research and Therapy, 35(8), 741-756.

Ruben, M. A., Hall, J. A., \& Schmid Mast, M. (2015). Smiling in a job interview: When less is more. The Journal of Social Psychology, 155(2), 107-126.

Rubin, K. H., \& Burgess, K. B. (2001). Social withdrawal and anxiety. In M. V. Vasey \& M. R. Dadds (Eds.), The developmental psychopathology of anxiety (pp. 407-434). Oxford University Press.

Sandoval-Norton, A. H., \& Shkedy, G. (2019). How much compliance is too much compliance: Is long-term ABA therapy abuse? Cogent Psychology, 6(1), 1641258.

Sasson, N. J., Faso, D. J., Nugent, J., Lovell, S., Kennedy, D. P., \& Grossman, R. B. (2017). Neurotypical peers are less willing to interact with those with autism based on thin slice judgments. Scientific Reports, 7, 40700.

Sasson, N. J., \& Morrison, K. E. (2019). First impressions of adults with autism improve with diagnostic disclosure and increased autism knowledge of peers. Autism, 23(1), 50-59.

Schlenker, B. R. (1980). Impression management: The self-concept, social identity, and interpersonal relations. Brooks/ Cole.

Schlenker, B. R., \& Leary, M. R. (1982). Social anxiety and selfpresentation: A conceptualization model. Psychological Bulletin, 92(3), 641.

Schneid, I., \& Raz, A. E. (2020). The mask of autism: Social camouflaging and impression management as coping/normalization from the perspectives of autistic adults. Social Science \& Medicine, 248, 112826.

Schuck, R. K., Flores, R. E., \& Fung, L. K. (2019). Brief report: Sex/gender differences in symptomology and camouflaging in adults with autism spectrum disorder. Journal of Autism and Developmental Disorders, 49(6), 2597-2604.

Sheppard, E., Pillai, D., Wong, G. T. L., Ropar, D., \& Mitchell, P. (2016). How easy is it to read the minds of people with autism spectrum disorder? Journal of Autism and Developmental Disorders, 46(4), 1247-1254.

Smart, L., \& Wegner, D. M. (1999). Covering up what can't be seen: Concealable stigma and mental control. Journal of Personality and Social Psychology, 77(3), 474-486. 
Sng, C. Y., Carter, M., Stephenson, J., \& Sweller, N. (2020). Partner perceptions of conversations with individuals with autism spectrum disorder. Journal of Autism and Developmental Disorders, 50, 1182-1197.

Sprecher, S. (2014). Effects of actual (manipulated) and perceived similarity on liking in get-acquainted interactions: The role of communication. Communication Monographs, 81(1), 4-27.

Sprecher, S., Treger, S., \& Wondra, J. D. (2013). Effects of selfdisclosure role on liking, closeness, and other impressions in get-acquainted interactions. Journal of Social and Personal Relationships, 30(4), 497-514.

Taylor, C. T., \& Alden, L. E. (2010). Safety behaviors and judgmental biases in social anxiety disorder. Behaviour Research and Therapy, 48(3), 226-237.
Ullman, S. E. (2007). A 10-year update of 'review and critique of empirical studies of rape avoidance'. Criminal Justice and Behavior, 34(3), 411-429.

Wechsler, D. (2009). Test of premorbid functioning: UK edition. Pearson Press.

Xie, S. Y., Flake, J. K., \& Hehman, E. (2019). Perceiver and target characteristics contribute to impression formation differently across race and gender. Journal of Personality and Social Psychology, 117(2), 364-385.

Zapf, D., \& Einarsen, S. (2003). Individual antecedents of bullying. In S. Einarsen, H. Hoel, D. Zapf, \& C. Cooper (Eds.), Bullying and emotional abuse in the workplace: International perspectives in research and practice (pp. 165-184). CRC Press. 